\title{
Erratum to: Study protocol for a multicenter investigation of reablement in Norway
}

Eva Langeland ${ }^{1,2^{*}}$, Hanne Tuntland ${ }^{1,3}$, Oddvar Førland ${ }^{1,4}$, Eline Aas ${ }^{5,6}$, Bjarte Folkestad $^{1,7}$, Frode F. Jacobsen ${ }^{1}$ and Ingvild Kjeken ${ }^{5,8,9}$

Unfortunately, the original version of this article [1] contained an error. The name of the author Eva Langeland was incorrectly spelt as Eva Langland. The correct spelling, Eva Langeland, has been included in the author list above.

\begin{abstract}
Author details
${ }^{1}$ Centre for Care Research Western Norway, Bergen University College, P.O Box 7030, 5020 Bergen, Norway. ${ }^{2}$ Department of Nursing, Bergen University College, P.O Box 7030, 5020 Bergen, Norway. ${ }^{3}$ Departement of Occupational Therapy, Physiotherapy and Radiography, Bergen University College, P.O Box 7030, 5020 Bergen, Norway. ${ }^{4}$ Haraldsplass Deaconess University College, Ulriksdal 10, 5009 Bergen, Norway. ${ }^{5}$ Institute of Health and Society, Research Centre for Habilitation and Rehabilitation Models and Services (CHARM), Faculty of Medicine, University of Oslo, P.O Box 1089, Blindern 0318, Oslo, Norway. ${ }^{6}$ Department of Health Management and Health Economics, University of Oslo, P.O Box 1089, Blindern 0318, Oslo, Norway. ${ }^{7}$ Uni Research Rokkan Centre, P.O Box 7810, 5020 Bergen, Norway. ${ }^{8}$ Diakonhjemmet Hospital, National Advisory Unit on Rehabilitation in Rheumatology, P.O. Box 23, Vinderen 0319, Oslo, Norway. ${ }^{9}$ Oslo and Akershus University College of Applied Sciences, Program of Occupational Therapy, Prosthetics and Orthotics, P.O. Box 4, St. Olavs plass, 0130 Oslo, Norway.
\end{abstract}

Received: 1 October 2015 Accepted: 1 October 2015

Published online: 09 October 2015

\section{Reference}

1. Langland E, Tuntland H, Førland O, Aas E, Folkestad B, Jacobsen FF, et al. Study protocol for a multicenter investigation of reablement in Norway. BMC Geriatr. 2015;15:111

\footnotetext{
* Correspondence: eva.langeland@hib.no

${ }^{1}$ Centre for Care Research Western Norway, Bergen University College, P.O Box 7030, 5020 Bergen, Norway

${ }^{2}$ Department of Nursing, Bergen University College, P.O Box 7030, 5020 Bergen, Norway

Full list of author information is available at the end of the article
}

\section{Submit your next manuscript to BioMed Central and take full advantage of:}

- Convenient online submission

- Thorough peer review

- No space constraints or color figure charges

- Immediate publication on acceptance

- Inclusion in PubMed, CAS, Scopus and Google Scholar

- Research which is freely available for redistribution 